\title{
PERILAKU PENJAMAH MAKANAN DI CATERING ANUGERAH DAN SEKAR KOTA MAKASSAR
}

Food Guarantee Behavior In Grace And Sekar Catering Makassar City Juherah $^{1}$, Irmawati ${ }^{2}$

${ }^{12}$ Poltekkes Kemenkes Makassar

*) kesling_mks@gmail.com

\begin{abstract}
Food handlers greatly affect the quality of the food, so that either directly or indirectly may affect the spread of the disease. Hiegene quality and sanitation is influenced by two factors food handlers and environmental factors, food contamination caused by factors handlers that knowledge of health behavior and body hygiene of food handlers. The purpose of this study was to determine fairy food handler on site catering and catering Sekar Award. This research is observational descriptive approach to obtain factual data on the behavior of food handlers in place Catering Award and Sekar city of Makassar, especially in Catering Award and Sekar who are on the Faisal and Minasaupa 173.

The results of this study showed that the distribution of respondents' level of knowledge ie knowledge indicates that the level of penegtahuan are categorized either as many as 3 people (15\%) categories quite 7 (35\%) and the category of less than 10 people (50\%), attitude menjukkan that the level of knowledge categorized well as much as 4 people (20\%) categories quite 6 (30\%) and the category of less than 10 (50\%), the action shows that the level of knowledge that are categorized either as many as six people (30\%) categories quite 3 people (10\%) and category less than 11 (55\%). It can be concluded from the behavior of food handlers who do not qualify ie $100 \%$ of the total, namely knowledge, attitudes and actions. So it is suggested to the manager of Catering for food handlers need to pay attention to the behavior and in order to do counseling, guidance and vocational training on individual hiegiene.

Keywords : Food Handler Behaviors
\end{abstract}

\section{ABSTRAK}

Penjamah makanan sangat berpengaruh terhadap kualitas makanan, sehingga baik secara langsung maupun secara tidak langsung dapat berpengaruh terhadap penyebaran penyakit. Kualitas hiegene dan sanitasi yang di pengaruhi oleh dua faktor penjamah makanan dan faktor lingkungan, terkontaminasinya makanan disebabkan oleh faktor pengetahuan penjamah yaitu dari perilaku sehat dan kebersihan badan penjamah makanan. Tujuan penelitian ini adalah untuk mengetahui periku penjamah makanan di tempat catering Anugerah dan catering Sekar. Jenis penelitian ini bersifat observasional dengan pendekatan deksriptif untuk memperoleh data faktual dari perilaku penjamah makanan ditempat Catering Anugerah dan sekar dikota Makassar khususnya di Catering Anugerah dan Sekar yang berada dijalan faisal dan Minasaupa 17 No.3. Hasil penelitian ini menunjukkan bahwa distribusi responden tingkat pengetahuan yaitu pengetahuan menunjukkan bahwa tingkat penegtahuan yang dikategorikan baik sebanyak 3 orang $(15 \%)$ kategori cukup 7 orang $(35 \%)$ dan kategori kurang 10 orang $(50 \%)$, sikap menjukkan bahwa tingkat pengetahuan yang dikategorikan baik sebanyak 4 orang $(20 \%)$ kategori cukup 6 orang $(30 \%)$ dan kategori kurang $10(50 \%)$, tindakan menunjukkan bahwa tingkat pengetahuan yang dikategorikan baik sebanyak 6 orang (30\%) kategori cukup 3 orang (10\%) dan kategori kurang 11 (55\%). Dari hasil penelitian dapat disimpulkan perilaku penjamah makanan yang tidak memenuhi syarat yaitu $100 \%$ dari jumlah keseluruhan yaitu pengetahuan, sikap dan tindakan. Sehingga disarankan kepada pihak pengelola Catering untuk perlu memperhatikan perilaku penjamah makanan dan agar dilakukan penyuluhan, bimbingan serta kursus keterampilan tentang hiegiene perorangan.

Kata Kunci : Perilaku Penjamah Makanan

\section{PENDAHULUAN}

Makanan adalah setiap benda padat atau cair yang apabila ditelan akan memberi suplai energi kepada tubuh untuk pertumbuhan atau berfungsinya tubuh. Kualitas higiene dan sanitasi yang dipengaruhi oleh dua faktor penjamah makanan dan faktor lingkungan dimana makanan tersebut diolah, termasuk fasilitas pengolahan makanan yang tersedia.

Meningkatnya kebutuhan masyarakat terhadap makanan yang disediakan diluar rumah, maka produk-produk yang disediakan oleh perusahaan dan perorangan yang bergerak dalam usaha penyediaan makanan untuk kepentingan umum, haruslah terjamin kesehatan dan keselamatannya. Sebagai salah satu jenis pelayanan umum yang mengolah dan menyediakan maka penjual makanan memiliki potensi yang cukup besar untuk menimbulkan gangguan kesehatan atau penyakit bawaan makanan yang dihasilkan disajikan dan dijual oleh penjual makanan harus memenuhi syarat kesehatan seperti faktor lokasi dan pembangunan, fasilitas sanitasi, peralatan, pengolahan makanan yang baik dan penjamah makanannya sendiri (Depkes R.I, 2010).

Data yang diperoleh dari dinas kesehatan Kota Makassar, kasus keracunan pangan di Indonesia pada tahun 2011 disebabkan oleh pangan jasa boga $30 \mathrm{KLB}$ (23.4 insiden \%), pangan olahan $16 \mathrm{KLB}$ (12.50\%), pangan jajanan 16 KLB (12.50 \%), dan lain-lain 8 KLB (6.25 \%). Pada tahun 2013 menurut BPOM berdasarkan insiden 
keracunan nasional, makanan masih menjadi penyebab tertinggi terjadinya keracunan (BPOM, 2013). Di antara kasus-kasus keracunan pangan, produk makanan yang berasal dari jasaboga (katering) ternyata memberikan kontribusi tertinggi dalam kasus keracunan makanan. Beberapa kasus keracunan makanan dikota makassar. Menurut Badan Pengawas Obat dan Makanan (BPOM) tahun 2003, Pekerja yang menangani pangan dalam suatu industri pangan merupakan sumber kontaminasi yang penting, karena kandungan mikroba patogen pada manusia dapat menimbulkan penyakit yang ditularkan melalui makanan.

Beberapa faktor terjadinya keracunan makanan dapat diakibatkan karena aspek pengolah makanan, peralatan, bahan makanan dan tempat pengelolaan makanan. Terkontaminasinya makanan terutama disebabkan oleh berbagai faktor antara lain pengetahuan penjamah makanan masih rendah termasuk perilaku sehat, kebersihan badan penjamah makanan, kebersihan alat makan dan sanitasi makanan. Peran penjamah makanan sangat penting dan merupakan salah satu faktor dalam penyediaan makanan yang memenuhi syarat kesehatan. Makanan dan minuman yang terkontaminasi oleh bakteri dapat menimbulkan infeksi maupun keracunan makanan jika dikonsumsi dan masuk ke dalam tubuh.

Penjamah makanan ini mempunyai peluang untuk menularkan penyakit. Banyak infeksi yang ditularkan melalui penjamah makanan, antara lain staphylococus aereus ditularkan melalui hidung dan tenggorokan, kuman clostridium perfringens, streptococcus, salmonella dapat ditularkan melalui kulit. Oleh sebab itu penjamah makanan harus selalu dalam keadaan sehat dan terampil.

Perilaku penjamah makanan sangat berpengaruh terhadap kualitas makanan, sehingga baik secara langsung maupun secara tidak langsung dapat berpengaruh terhadap penyebaran penyakit. Kebiasaan mencuci tangan sebelum melakukan pekerjaan pengolahan makanan adalah mutlak dilaksanakan, karena tangan tidak pernah bebas dari berbagai macam kuman, baik berasal dari kontaminasi maupun yang tinggal secara menetap pada tangan.

Catering adalah istilah umum untuk wirausaha yang melayani pemesanan berbagai macam masakan (makanan dan minuman) baik untuk pesta maupun untuk suatu instansi. Dari hasil penjelasan diatas alasan penulis mengambil tempat catering karena, ditempat catering orang yang secara langsung berhubungan dengan makanan dan peralatan mulai dari tahap persiapan, pembersih, pengolahan, pengangkutan sampai dengan penyajian, Catering Anugerah dan Sekar catering yang termasuk terbesar dikota Makassar dan yang paling banyak diminati oleh masyarakat. Berdasarkan latar belakang diatas maka penulis tertarik melakukan penelitian dengan judul "Studi Periku Penjamah Makanan ditempat Catering Anugerah dan sekar Kota makassar 2016".

Adapun tujuan dari penelitian ini adalah :

1. Tujuan umum

Untuk mengetahui periku
penjamah makanan di Catering
Anugerah dan Catering Sekar.

2. Tujuan khusus

Untuk mengetahui periku penjamah makanan dalam pengolahan makanan di Catering Anugerah dan Sekar kota Makassar :

a. Untuk mengetahui Pengetahuan penjamah makanan dicatering Anugerah dan Sekar.

b. Untuk mengetahui Sikap penjamah makanan dicatering Anugerah dan Sekar.

c. Untuk mengetahui praktek/tindakan dicatering Anugerah dan Sekar.

\section{METODE}

Jenis Penelitian

Penelitian ini bersifat observasional dengan pendekatan deksriptif untuk memperoleh data faktual dari perilaku penjamah makanan ditempat Catering dikota Makassar khususnya di Catering Anugerah dan Sekar yang berada dijalan faisal dan Minasaupa 17 No.3.

\section{Gambaran Umum Lokasi \\ 1. Lokasi Penelitian}

Pengambilan sampel dilakukan di Kota Makassar khususnya ditempat Catering Anugerah yang berada di Jalan Faisal dan pada Catering Sekar yang berada di Minasaupa.

2. Waktu Penelitian

Penelitian ini dilaksanakan pada bulan Mei 2016 


\section{Variabel Penelitian}

Variabel Bebas: Pengetahuan, Sikap, dan

Tindakan

Variabel Terikat: Perilaku

Variabel Pengganggu: Pendidikan dan Umur

\section{Definisi Operasional}

Untuk memberikan kesamaan pengertian dalam penelitian ini, maka penulis memberikan pengertian sebagai berikut :

a. Catering adalah istilah umum untuk wirausaha yang melayani pemesanan berbagai macam masakan (makanan dan minuman) baik untuk pesta maupun untuk suatu instansi.

b. Pengetahuan penjamah makanan adalah segala sesuatu yang diketahui oleh penjamah mengenai hygiene sanitasi makanan.

c. Sikap adalah tanggapan penjamah makanan tentang hygiene sanitasi makanan.

d. Tindakan adalah pelaksaan secara nyata apa yang disebut dalam teori: teorinya mudah, tetapi praktiknya sukar pelaksanaan pekerjaan.

e. Penjamah makanan adalah orang/karyawan yang menangani makanan di Catering Anugrah, dan sekar mulai dari mempersiapkan bahan sampai pada pengolahan menjadi makanan yang siap untuk disajikan.

f. Perilaku penjamah makanan yang dimaksud adalah tingkah laku penjamah makanan pada waktu mengolah makanan seperti menggaruk kepala, bercerita, hygiene perorangan, menggunakan APD (celemek, tutup kepala, masker).

g. Pendidikan yang dimaksud adalah tingkat pendidkan terakhir penjamah makanan.

h. Umur yg dimaksud adalah tingakat umur penjamah makanan.

\section{Kriteria objektif}

a. Pengetahuan penjamah makanan

1) Baik, bila responden mampu menjawab $100 \%$ dari sejumlah pertanyaan yang di sediakan.

2) Cukup, bila responden mampu menjawab $\geq 66,7 \%$ dari sejumlah pertanyaan yang disediakan.

3) Kurang, bila responden hanya mampu menjawab < 66,7\% dari sejumlah pertanyaan yang disediakan b. Sikap penjamah makanan

1) Baik, bila responden mampu menjawab $100 \%$ dari sejumlah pertanyaan yang di sediakan.

2) Cukup, bila responden mampu menjawab $\geq 66,7 \%$ dari sejumlah pertanyaan yang disediakan.

3) Kurang bila responden hanya mampu menjawab < 66,7\% dari sejumlah bobot yang disedikan.

c. Praktek/tindakan penjamah makanan

1) Baik, bila responden mampu menjawab $100 \%$ dari sejumlah pertanyaan yang di sediakan.

2) Cukup, bila responden mampu menjawab $\geq 66,7 \%$ dari sejumlah pertanyaan yang disediakan.

3) Kurang bila responden hanya mampu menjawab < 66,7\% dari sejumlah bobot yang disedikan.

d. Perilaku dari pengetahuan, sikap dan tindakan

1) Baik, bila responden mampu menjawab $100 \%$ dari sejumlah pertanyaan yang di sediakan.

2) Cukup, bila responden mampu menjawab $\geq 66,7 \%$ dari sejumlah pertanyaan yang disediakan.

3) Kurang bila responden hanya mampu menjawab < 66,7\% dari sejumlah bobot yang disedikan.

\section{Populasi dan Sampel}

a. Populasi

Dalam penelitian ini yang menjadi populasi adalah tenaga penjamah makanan yang langsung mengolah makanan ditempat catering Anugerah dan Sekar beserta alasan peneliti mengambil hanya 2 Catering karena adanya keterbatasan waktu pada peneliti dan yang diwawancarai..

b. Sampel

Jumlah sampel 2 (Dua) catering yaitu Catering Anugerah, Sekar dengan teknik pengambilan sampel yaitu semua penjamah makanan yang mengolah makanan dicatering Anugerah 10 orang, Sekar 10 orang, sehingga total sampling 20 orang.

\section{Teknik Analisa Data}

Data yang diperoleh dari kuesioner, lembar observasi diolah secara manual dan di uraikan dalam bentuk tabel. Dianalisa secara deskriftif. 


\section{HASIL}

Berdasarkan hasil penelitian yang telah diperoleh dengan mengadakan wawancara dan observasi terhadap penjamah makanan di tempat catering Anugerah di jalan Faisal dan Catering Sekar di Jalan Minasaupa, serta menggunakan kuesioner dan pengamatan langsung terhadap responden yaitu 10 orang di catering Anugerah dan 10 orang di Catering Sekar, maka didapatkan hasil sebagai berikut:

\section{Tingkat Pengetahuan Makanan}

Penjamah

Hasil penelitian tingkat pengetahuan. penjamah makanan di Catering Anugerah dan Sekar kota Makassar di tunjukkan pada tabel 1 berikut ini:

Tabel 1

Distribusi Pengetahuan Responden di Catering Anugerah dan Sekar

\begin{tabular}{|c|c|c|c|c|c|}
\hline \multirow[b]{2}{*}{ No } & \multirow[b]{2}{*}{$\begin{array}{c}\text { Kriteria } \\
\text { penilaian }\end{array}$} & \multicolumn{2}{|c|}{$\begin{array}{l}\text { Catering Anugerah } \\
\text { Hasil }\end{array}$} & \multicolumn{2}{|c|}{$\begin{array}{l}\text { Catering Sekar } \\
\text { Hasil }\end{array}$} \\
\hline & & Jumlah & $\%$ & Jumlah & Hasil $\%$ \\
\hline 1 & Baik & 2 & 20 & 1 & 10 \\
\hline 2 & Cukup & 3 & 30 & 4 & 40 \\
\hline 3 & Kurang & 5 & 50 & 5 & 60 \\
\hline & Jumlah & 10 & 100 & 10 & 100 \\
\hline
\end{tabular}

\section{Sikap Penjamah Makanan}

Tabel 2

Distribusi Sikap Penjamah Makanan di Catering Anugerah dan Sekar

\begin{tabular}{rlcccc}
\hline & Kriteria & \multicolumn{2}{c}{$\begin{array}{c}\text { Catering Anugerah } \\
\text { Hasil }\end{array}$} & \multicolumn{2}{c}{$\begin{array}{c}\text { Catering Sekar } \\
\text { Hasil }\end{array}$} \\
No & penilaian & Jumlah & $\%$ & Jumlah & $\%$ \\
\hline 1 & Baik & 3 & 30 & 1 & 10 \\
2 & Cukup & 3 & 30 & 3 & 30 \\
3 & Kurang & 4 & 40 & 6 & 60 \\
& Jumlah & 10 & 100 & 10 & 100 \\
\hline
\end{tabular}

\section{Tindakan Penjamah Makanan}

Tabel 3

Distribusi Tindakan Penjamah Makanan di Catering Anugerah

\begin{tabular}{cccccc}
\hline \multicolumn{5}{c}{ Catering Anugerah } \\
\hline \multicolumn{1}{c}{$\begin{array}{c}\text { Catering Anugerah } \\
\text { Hasil }\end{array}$} & \multicolumn{2}{c}{$\begin{array}{c}\text { Catering Sekar } \\
\text { Hasil }\end{array}$} \\
No & $\begin{array}{c}\text { Kriteria } \\
\text { penilaian }\end{array}$ & Jumlah & $\%$ & Jumlah & $\%$ \\
& & 4 & 40 & 2 & 20 \\
\hline 1 & Baik & 2 & 20 & 1 & 10 \\
2 & Cukup & 4 & 40 & 7 & 70 \\
3 & Kurang & 10 & 100 & 10 & 100 \\
\hline & Jumlah & 10 & & &
\end{tabular}

\section{Perilaku Penjamah Makanan}

Tabel 4

Distribusi Perilaku Penjamah Makanan di Catering Anugerah dan Sekar

\begin{tabular}{|c|c|c|c|c|c|c|}
\hline No & $\begin{array}{c}\text { Kriteria } \\
\text { penilai } \\
\text { an }\end{array}$ & Pengetahuan & $\begin{array}{l}\text { Sik } \\
\text { ap }\end{array}$ & $\begin{array}{c}\text { Tindaka } \\
\mathbf{n}\end{array}$ & $\begin{array}{c}\text { Tota } \\
\text { I }\end{array}$ & $(\%)$ \\
\hline 1 & Baik & 3 & 4 & 6 & 13 & $\begin{array}{c}21, \\
7\end{array}$ \\
\hline 2 & Cukup & 7 & 6 & 3 & 16 & $\begin{array}{c}26, \\
7\end{array}$ \\
\hline 3 & Kurang & 10 & 10 & 11 & $\overline{31}$ & $\begin{array}{c}51, \\
6\end{array}$ \\
\hline \multicolumn{2}{|c|}{ Jumlah } & 20 & 20 & 20 & 60 & 100 \\
\hline
\end{tabular}

\section{PEMBAHASAN}

\section{Tingkat Pengetahuan Penjamah Makanan}

Berdasarkan hasil wawancara tingkat pengetahuan penjamah makanan pada Catering Anugerah dan Sekar di jalan faisal dan Minasaupa di kota Makassar menunjukkan bahwa tingkat pengetahuan pada Catering Anugerah dan Sekar dinyatakan masih mempunyai pengetahuan yang kurang. Pengetahuan merupakan hasil dari tahu, tahu diartikan sebagai mengingat suatu materi yang telah dipelajari sebelumnya.terjadi setelah orang melakukan pengindraan terhadap suatu obyek tertentu. Pengindraan terjadi melalui pancaindra manusia, yakni indra penglihatan, pendengaran, penciuman, rasa dan raba. Sebagian besar pengetahuan manusia diperoleh melalui mata dan telinga (Notoatmodjo, 2007).

Pada tabel 1 dapat dilihat pada Catering Anugerah dan sekar bahwa diperoleh dari 20 penjamah makanan, menunjukkan bahwa tingkat penegtahuan yang dikategorikan baik sebanyak 3 orang $(15 \%)$ kategori cukup 7 orang $(35 \%)$ dan kategori kurang 10 orang (50\%).

Berdasarkan data diatas bahwa Catering Anugerah masih memiliki pengetahuan kurang penelitian ini ditemukan adanya ketidak tahuan penjamah makanan tentang kebersihan diri, dan ketidak tahuan bagaimana mengolah makanan yang baik hal ini akan meningkatkan resiko kontaminasi antara makanan dengan penjamah makanan, karena kebersihan diri seorang penjamah makanan merupakan sebuah kunci utama terciptanya higiene sanitasi makanan.

$$
\text { Pada Catering Sekar yang }
$$

berpengetahuan memiliki pengetahuan kurang, dimana penjamah makanan tidak menggunakan alat pelindung diri mereka hanya memakai sebagian alat pelindung diri seperti tidak menggunakan masker, sarung 
tangan, penutup kepala, dan tidak menggunakan pakaian kerja karena mereka tidak mengetahui manfaat menggunakan alat pelindung diri pada saat bekerja adalah untuk meminimalkan risiko kecelakaan kerja dan penyakit akibat kerja. Faktor lain yang dapat berpengaruh adalah pemeriksaan kesehatan secara berkala yang tidak diterapkan, serta pemeriksaan awal sebelum masuk kerja.

Dapat kita lihat dari hasil diatas bahwa Pengetahuan sangat penting bagi semua orang untuk dapat mengetahui segala hal apapun, sehingga kita dapat mengetahui hal yang tidak diketahui menjadi tahu hal tersebut. Pengetahuan diperoleh dari informasi baik secara lisan ataupun tertulis dari pengalaman seseorang. Pengetahuan diperoleh dari fakta ataupun kenyataan dengan radio, melihat televisi, dan sebagainya. Serta dapat diperoleh dari pengalaman berdasarkan pemikiran kritis (Dewi susanna,2003).

Ada beberapa faktor yang dapat mempengaruhi pengetahuan yaitu pendidikan, usia dan sumber informasi, Meskipun pengetahuan sangat penting, tetapi pada kenyataan masih banyak penjamah/masyarakat yang tidak memperdulikan pentingnya pengetahuan pada saat mengolah makanan. penjamah makanan tidak memperdulikan pengetahuan di sebabkan karna tidak peduli pada informasi yang ada.

Oleh sebab itu diharapkan kepada pemilik usaha agar memberikan kursus atau penyuluhan kepada pihak penjamah makanan, agar dapat lebih mengetahui bagamaimana cara menjamah makanan yang hiegienis pada saat mengolah makanan.

salah satu penyebab hal tersebut adalah kurang kesadaran dari orang tersebut dan kebiaasaan yang kurang. Dari hasil wawancara kurangnya diberikan kursus atau penyuluhan pada pengolah/penjamah makanan dan tidak diberikan pembinaan dengan baik serta mereka belum mengerti setelah melihat atau menyaksikan, mengalami atau diajar pengalaman tenaga pengolah makanan yang masih kurang dan sedikit dalam hal pengolahan makanan dan belum pernah mengikuti pelatihan tentang higiene dalam pengolahan makanan.

Adapun penyebab jika seseorang tidak memiliki pengetahuan yang kurang yaitu mempunyai pengalaman yang kurang dan dilain pihak tentang informasi, referensi yang masuk kurang dimengerti bahkan tidak dapat diketahui sama sekali. Salah satu untuk mengatasi ketidak tahuan yaitu untuk pemilik usaha Catering Anugerah dan Sekar agar memberikan penyuluhan setiap 2 kali setahun serta memberikan kursus setiap 6 bulan sekali kepada pengolah makanan/penjamah makanan agar mereka tahu tentang kebersihan diri dalam mengolah makanan.

\section{Sikap Penjamah Makanan}

Sikap adalah reaksi atau atasu respon yang masih tertutup dari seseorang terhadap suatu stimulus atau obyek. Menifestasi sikap tidak dapat langsung dilihat, tetapi hanya dapat ditafsirkan terlebih dahulu terhadap perilaku yang tertutup. Sikap secara nyata menunjukkan konotasi adanya kesesuaian reaksi dengan stimulus tertentu yang dalam kehidupan sehari-hari merupakan reaksi bersifat emosional terhadap stimulus sosial.

Pada tabel 2 dapat dilihat pada Catering Anugerah dan Sekar bahwa dari tingkat sikap yang diperoleh dari 20 penjamah makanan, menunhukkan bahwa tingkat pengetahuan yang dikategorikan baik sebanyak 4 orang (20\%) kategori cukup 6 orang (30\%) dan kategori kurang 10 (50\%).

Sikap yang pada Catering Anugerah juga masih kurang mereka tidak memperhatikan pada saat mengolah makanan bercerita ditempat pengolahan, akibat berbicara saat mengolah makanan dapat mengakibatkan terkontaminasinya makanan. Sedangkan pada sekar masih sangat kurang, mereka masih sering belum memperhatikan bahwa sikap yang dilakukan pada saat mengolah makanan mengakibatkan adanya makanan yang dapat terkontaminasi dan tidak menciptakan makanan yang mudah terkontaminasi, seperti para penjamah pada saat menjamah makanan mereka menggarukgaruk kepala pada saat menjamah makanan, serta berbicara saat mengolah makanan.

Berdasarkan data diatas bahwa sikap penjamah makanan dikategorikan masih kurang salah satu penyebab hal tersebut yaitu adalah penjamah makanan tidak memakai celemek dan penutup kepala serta masih ada beberapa pekerja yang tidak menggunakan pakaian kerja bahkan tidak mencuci tangan sebelum mengolah makanan. Sehingga dapat terjadi pencemaran langsung (Direct contamination) terhadap makanan yang bersifat ketidak tahuan/kelalaian baik disengaja maupun tidak di sengaja seperti potongan rambut yang masuk pada makanan. Selain dari hasil pengamatan diketahui 
bahwa sikap penjamah makanan adalah banyak berbicara/cerita pada waktu mengolah makanan. Kebiasaan ini merupakan kebiaasaan buruk karena percikan air ludah yang keluar waktu berbicara dapat mencemari makanan secara langsung. Apabila seorang penjamah makanan menderita penyakit menular seperti tuberclosis (TBC) dan percikan air ludah yang masuk kedalam makanan dan dimakan oleh konsumen maka secara langsung dapat tertular.

\section{Tindakan Penjamah Makanan}

Suatu tindakan belum otomatis terwujud dalam suatu tindakan (overt behaviour). Untuk mewujudkan sikap menjadi suatu perbuatan nyata diperlukan faktor pendukung atau suatu kondisi yang memungkinkan. Antara lain adalah fasilitas. Disamping faktor fasilitas, juga perlu faktor dukungan (support) dari pihak lain. Praktek ini mempunyai beberapa tindakan.

Pada tabel 3 dapat dilihat pada Catering Anugerah dan Sekar bahwa dari tindakan yang diperoleh dari 20 penjamah makanan, menunjukkan bahwa tingkat pengetahuan yang dikategorikan baik sebanyak 6 orang $(30 \%)$ kategori cukup 3 orang $(10 \%)$ dan kategori kurang 11 (55\%).

Berdasarkan data diatas pada Catering Anugerah tindakan pada penjamah makanan pada saat menolah makanan masih terdapat penjamah yang tidak menjaga kebersihan diri, juga terdapat orang yang bersin pada saat bersin penjamah makanan menggunakan tangan, hal itu dapat terkontaminasi pada makanan, peyebabab hal tersebut karena kurangnya kesadaran bagi penjamah makanan dan kurangnya perilaku untuk menghindari hal tersebut untuk dilakukan penyuluhan bagi para penjamah.

Pada Catering Sekar bahwa tindakan penjamah makanan juga masih sangat kurang karna pengolah/penjamah makanan masih sangat kurang dalam memperhatikan kebersihan diri, tidak memakai pakaian kerja yang rapi dan bersih, serta memperhatikan tempat pengolahan makanan agar membersihkan tempat pengolahan makanan supaya pada saat mengolah makanan tempat pengolahan makanan tidak kotor, tidak dapat terkontaminasi oleh bakteri dan pada saat mengolah makanan kita merasa nyaman karena memiliki ruangan pengolahan makanan yang bersih dan nyaman.

\section{Perilaku penjamah makanan}

Dari tabel 4 perilaku penjamah makanan dapat dilihat pada Catering Anugerah dan Sekar bahwa dari tingkat perilaku yang diperoleh dari 20 penjamah makanan, menunjukkan bahwa kategori kurang $31(51,6 \%)$ dapat di simpulkan bahwa perilaku penjamah makanan di Catering Anugerah dan Sekar tidak memenuhi syarat dari jumlah keseluruhan yaitu $100 \%$.

Adapun perilaku penjamah makanan di Catering Anugerah dan Sekar bahwa perilaku dalam pengolahan menjamah makanan dipengaruhi oleh pengetahuan, sikap, dan tindakan kebiasaan yang sering ditemukan adalah berbicara saat mengolah makanan, tidak memakai alat pelindung diri (APD) dengan lengkap bahkan ada yang tidak menggunakan alat pelindung diri (APD) sama sekali, pakaian kerja, kebersihan diri dari seorang penjamah makanan masih kurang serta tempat pengolahan makanan yang masih kotor karena kurangnya pengetahuan, sikap dan tindakan yang dilakukannya, catering Anugerah dan sekar dikategorikan masih belum memenuhi syarat.

Adapun dari perbandingan penelitian sebelumnya yaitu mereka masih susah mengubah perilaku penjamah makanan sampai saat ini. Di sarankan agar perilaku penjamah makanan pada Catering Anugerah agar mengubah perilaku penjamah makanan agar dapat menciptakan makanan yang sehat dan dapat dikomsumsi dengan baik bagi para konsumen Untuk memperoleh kualitas makanan yang memenuhi syarat perilaku :

a. Selalu memperhatikan hiegiene perorangan, menggunakan APD (celemek dan tutup kepala) saat mengolah makanan, serta tidak berbicara/bercerita saat mengolah makanan.

b. Menjaga kebersihan tangan, rambut, kuku, dan pakaian. Memakai celemek dan tutup kepala, Tidak sambil merokok, menggaruk anggota badan (telinga, hidung, mulut atau bagian lainnya)

c. Tidak batuk atau bersin dihadapan makanan jajanan yang disajikan dan atau tanpa menutup mulut atau hidung (Kepmenkes 942/Menkes/SK/VII/2003).

d. Kebersihan lantai harus diperhatikan supaya tidak mengundang lalat untuk hinggap. 
e. Tempat sampah yang kedap air dan tertutup harus tersedia ditempat pengolahan makanan.

f. Pertemuan antara lantai dan dinding dibuat melengkung agar mudah dibersihkan

\section{KESIMPULAN}

1. Pengetahuan penjamah makanan di catering Anugerah dan sekar jumlah penjamah 20 orang, yang memiliki pengetahuan kurang $13(21,6 \%)$.

2. Sikap penjamah makanan di catering Anugerah dan sekar jumlah penjamah 20 orang, yang memiliki sikap kurang 16 $(26,6 \%)$.

3. Tindakan penjamah makanan di catering Anugerah dan sekar jumlah penjamah 20 orang, yang memiliki tindakan kurang 31 $(51,6, \%)$.

\section{SARAN}

1. Kepada pengelola usaha Catering Anugerah dan Sekar perlu dilakukan penyuluhan tentang perilaku pada penjamah makanan untuk meningkatkan pengetahuan, sikap dan tindakan kebersihan perorangan penjamah makanan.

2. Agar pengetahuan, sikap dan tindakan serta kebersihan penjamah perlu diberikan perhatian atau pembinaan khusus untuk menghindarkan kejenuhan agar mereka tidak berperilaku dan berpenampilan (kebersihan) kurang baik.

3. Disarankan pada peneliti selanjutnya untuk meneliti kualitas bakteriologis dari kedua catering tersebut

\section{DAFTAR PUSTAKA}

Aminah, 2007: Studi Tentang Aspek Pengolahan Makanana dan Kualitas Bakteriologis Makanan Di Catering Glory. Makassar.

Depkes R.I, 2001: Kumpulan Modul Kursus Penyehatan Makanan bagi Pengusaha Makanan dan Minuman (http://wordpress.com/2012/03/19) Diakses 23 Desember 2015.

Dewi susanna, dkk; 2003: Pemantauan Kualitas Makanan Ketoprak Dan Gado-Gado Dilingkungan Kampus UI Depok Melalui Pemeriksaan Bakteriologi (http://repository.ui.ac.id/contents/koleksi/2/881.pdf). Diakses 10 juli 2016.

Erlani, dkk; 2015: Panduan Praktek Lapangan Sanitasi Tempat-Tempat Umum dan Pariwisata. Makassar.

Hiasinta A. Purnawijayanti; 2001: Sanitasi Higiene dan Keselamatan Kerja Dalam Pengolahan Makanan. Kasinius; Yogyakarta.

Mudiatun, dkk; 2012: Sanitasi Makanan Perilaku Penjamah Makanan (http://inspeksisanitasi.blogspot.co.id/2012/01) Diakses 4 Januari 2016.

Nunik Agustina Rahayu, 2013: Studi Deksriftip Karasteristik Hygiene Dan Sanitasi Pada Pengolahan Makanan Gado-Gado Lingkungan Pasar Johar. Semarang. (https://www.google.com/jurnal) Diakses 5 januari 2016.

Rizsa Puspitaningtyas, 2015: Upaya Penjamah Makanan Kualitas Ditinjau Dari Aspek Food Safety Pada Warung Makan Disekitar Universitas Negeri Semarang. (https://www.google.com/jurnal) Diakses 25 januari 2016.

Republik Indonesia; 2012: Kumpulan Modul Kursus Higiene Sanitasi Makanan dan Minuman; Jakarta.

Sri Rejeki, 2015. Sanitasi Hygiene dan k3 (Kesehatan Dan Keselamatan Kerja); Bandung.

Zaenab, dkk; 2013; Penyehatan Makanan Minuman-B; Makassar: Jurusan Kesehatan Lingkungan. 